Journal of Zhejiang University-SCIENCE A (Applied Physics \& Engineering)

ISSN 1673-565X (Print); ISSN 1862-1775 (Online)

www.zju.edu.cn/jzus; www.springerlink.com

E-mail: jzus@zju.edu.cn

Erratum:

\title{
Erratum to: Effect of thermal stratification on interflow travel time in stratified reservoir
}

\author{
Xiao-feng ZHANG ${ }^{1}$, Shi REN ${ }^{\dagger 1}$, Jun-qing $\mathrm{LU}^{2,3}$, Xin-hua $\mathrm{LU}^{1}$ \\ $\left({ }^{1}\right.$ State Key Laboratory of Water Resources and Hydropower Engineering Science, Wuhan University, Wuhan 430072, China) \\ $\left({ }^{2}\right.$ South China Institute of Environmental Science, Guangzhou 510655, China) \\ $\left({ }^{3}\right.$ State Environmental Protection Key Laboratory of Water Environmental Simulation and Pollution Control, Guangzhou 510655, China) \\ †E-mail: renshi@whu.edu.cn
}

http://dx.doi.org/10.1631/jzus.A14e0269

Erratum to: J Zhejiang Univ-Sci A (Appl Phys \& Eng) 2015 16(4):265-278 doi:10.1631/jzus.A1400269

The original version of this article unfortunately contained a mistake.

In p.275, the sentence "The theoretical travel time of interflow is larger than that measured in all conditions." should be "The theoretical travel time of interflow is smaller than that measured in all conditions." Meanwhile, the correct version of Fig. 13 is given below.

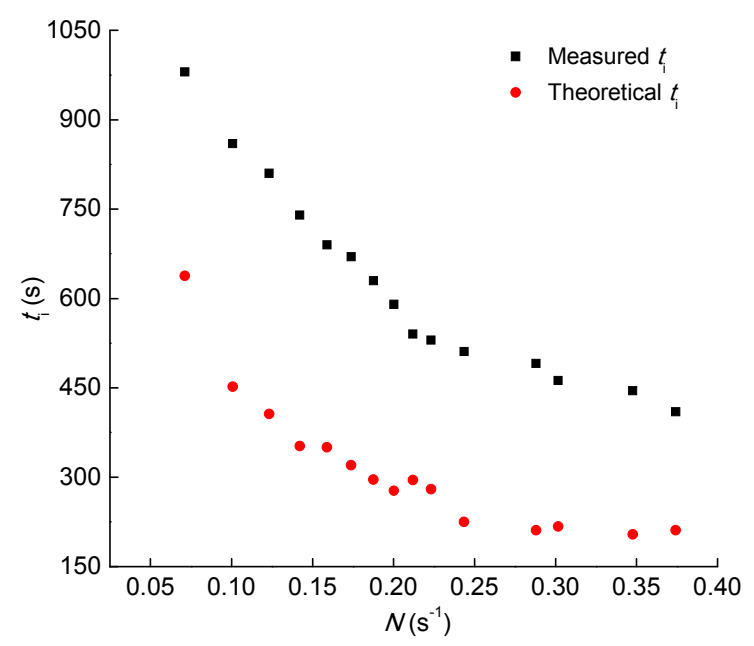

Fig. 13 Theoretical and measured travel times of the interflow in experiments and numerical simulations

The online version of the original article can be found at http://dx.doi.org/10.1631/jzus.A1400269 C) Zhejiang University and Springer-Verlag Berlin Heidelberg 2016 